\title{
Perceived Individual Risk of Co-innovation in Collaborative Innovation Networks
}

\author{
Kaveh Abhari \\ University of Hawai'i at Mānoa \\ abhari@hawaii.edu
}

\author{
Elizabeth J. Davidson \\ University of Hawai'i at Mānoa \\ edavidso@hawaii.edu
}

\author{
Bo Xiao \\ University of Hawai'i at Mānoa \\ boxiao@hawaii.edu
}

\begin{abstract}
Cultivating collective innovation while preserving the interest of the individual contributors is one of the main challenges collaborative innovation networks face. This challenge is riddled with difficulties in managing individuals' co-innovation risks. The first step toward understanding co-innovation risks is the development of a valid and reliable model to measure the actors' perception of risk. This paper conceptualizes co-innovation risk from actor's perspective. It also proposes and tests a nomological network that illustrates the effect of risk on coinnovation behavior.
\end{abstract}

\section{Introduction}

Co-innovation business models and strategies have transformational capacity in helping businesses develop new ideas and bring them to market [1]-[3]. External co-innovators, referred to as "actors" in this paper, are the main capitals for all co-innovation project. While many factors may ultimately impact success or failure of co-innovation projects, all else being equal, the success of a co-innovation project is contingent upon the amount and quality of the resources (e.g. time, knowledge) actors dedicate to the project. However, whether or not actors are willing to participate in co-innovation and dedicate their resources depends on the benefit and risk estimation of contribution. Understating the factors that affect actors' perception of benefits and risks is critical to maintaining the productivity of co-innovation. To this end, our paper focuses on risks that may discourage actors' participation and contribution.

While risks in co-innovation have been an area of Information Systems (IS) research interest [4], risks at the individual level have received less attention from academia compared to organizational risk. The research efforts to date have also led to inconclusive models of co-innovation behavior due to the absence of a comprehensive framework to examine the benefits and risks at the same time. To address this gap, this paper reports on the development of an instrument designed to conceptualize and measure the various aspects of co-innovation risk affecting co-innovation processes, namely ideation, collaboration, and communication [5]. Although the focus of this paper is on risk in co-innovation networks, the measurement instrument developed is applicable more generally to a variety of open innovations models.

In this paper, we focus on perceived risk of coinnovation (in short, co-innovation risk), defined as an actor's perception of potential losses in contributing to co-innovation, and conceptualized based on the characteristics of individual risk revealed in a case study. Measurement items were then developed on the basis of the case data and existing literature. The resulting instrument was subjected to a pilot test and a field study, and demonstrated acceptable levels of reliability and validity. The result is a 15-item instrument comprising four sub-scales, which provide a useful tool for the study of co-innovation risks and their relationships with actors' behaviors.

\section{Literature and theory}

Gloor [11: 4] defined a co-innovation network as "a cyberteam of self-motivated people with a collective vision, enabled by the Web to collaborate in achieving a common goal by sharing ideas, information, and work." Stakeholders in a coinnovation network typically come from diverse backgrounds to work collectively on problems presented to, or proposed by, members of the coinnovation network [3], [6]-[8]. With rapid growth and diffusion of social technologies, the co-innovation model has expanded to encompass networks of actors who not only contribute to innovation activities but also lead the process [9]-[13]. The application of social technologies in co-innovation [13], [14] extends open innovation beyond customer virtual community or open source community models to socially-engaged individual actors fully involved in all phases of new product development [6], [15]. This high level of participation can directly affect the value co-creation across the innovation cycle. Understanding factors affecting actors' participation, therefore, is crucial to improving the co-innovation process and outcomes. 


\subsection{Co-innovation risk}

Innovation is the function of creativity and risk taking [16]. However, there is a limited amount of empirical research on co-innovation risk management [17]. Previous studies mainly focused on mitigating the risks met by companies in their innovation process or on risk-sharing between co-innovators [18], [19]. For example, Enkel et al., discussed co-innovation risks such as loss of knowledge, higher coordination costs, loss of control, and higher complexity [20]. However, co-innovation risks are not limited to the organizational level; individual risk assessment is necessary when actors play key roles in co-innovation process [19]. Overlooking actor-related risks is regarded as a major threat to co-innovation [17].

Minimizing individual risks is at the heart of the risk management [21] and actor retention strategy in co-innovation networks [19]. Thus, to sustain the coinnovation process, understanding and addressing individual risks as one of the major hindrances would be worthwhile. At the actor level, the risk of coinnovation is conceptualized as the expectation of individual's losses due to the participation or contribution to co-innovation process. The perceived risks affect actors' intention to achieve co-innovation goals [22].

\subsection{Co-Innovation behavior and risk}

The co-innovation network business model defines the scope of external actors' involvement in coinnovation, which is the basis for understanding actor behavior. Subsuming variations in the scope of activities, Gloor proposes three general and fundamental dimensions of actor participation in collaborative communities: creativity, collaboration, and communication [1]. In co-innovation networks, creativity is referred to as ideation or co-creation of new product ideas [23]. The risk in the ideation process is mainly associated with losing the intellectual property right with the collaborators [24]. Another example is performance risk, which refers to the possibility that a new product or service is not performing as it was designed and, therefore, failing to deliver the benefits that were originally intended [25].

Collaboration involves interactions among internal and external actors to address problems and find or improve solutions [13]. Losing time and other resources over unsuccessful partnership are examples of risks associated with the collaboration efforts [26]. Because of the distributed nature of the co-innovation model, communication between actors such as sharing information and knowledge is an inherent aspect throughout co-innovation processes and activities [6]. Social or professional risks in an innovation community may limit communication among the actors [27]. An understanding of the relationship between risks and these dimensions is important for predicting actor behavior. The first step toward this goal is the development of a valid and reliable model to measure the actors' perception of risk.

\section{Method}

The construct development was carried out in six phases [28]. The first phase, the case study, helped with construct conceptualization. Studying the construct attributes in a natural setting supported measurement development [25], [26] by providing supplementary sources of evidence for the construct development [27]. The second phase was construct operationalization with the goal of creating pools of items from existing scales and the case study. Following these steps, the construct was developed and the scales were selected for further examination.

In the third phase, the scale and sub-scale were pretested for face validity and content validity. The fourth phase, the pre-test of the questionnaire helped ensure that the items are valid in co-innovation context. In the fifth phase, the pilot study, the instrument was distributed to a small sample of active co-innovators, and an analysis of the responses was conducted to establish the scales' reliability. Items that did not contribute to the reliability were culled for phase six, a full-scale field study. The field study was carried to further examine the instrument validity and reliability within the context. Sub-scales were further refined in this last phase. In this phase, we also explored the instrument's predictive validity.

\section{Construct development process}

To characterize co-innovation risk, we used the theory of perceived risk [29]-[31] and studied the connections between co-innovation activities and its undesirable consequences [24]. Then, we conducted a case study of a co-innovation network to supplement the literature for a better understanding of the perceived risks in the context.

The theory suggested that perceived risk can be conceptualized as a combination of uncertainty plus seriousness of outcome involved [30], and can be modeled as the expectation of losses associated with co-innovation [32]. To understand the co-innovation risk, we should consider expectation of losses in relationship to the actors' goals and expectations [33]. Therefore, it is sufficient to model the expectation of losses as the uncertainty of achieving personal coinnovation goals [34], [35]. To capture this concept, IS studies adapted consumer behavior literature and in particular, Cunningham's [36] six dimensions of 
perceived risk: financial, performance, social, time, safety, and psychological loss [31], [35], [37].

Perceived financial risk (or economic risk) is associated with the possible loss of money in the adaptation of an information system [38]. Financial risk in co-innovation business models is twofold: risk associated with the direct financial investment of actors, and the opportunity cost of investment in one network but not in the others [41]. Perceived performance risk refers to actor assessment of potential performance problems-malfunctioning, processing errors, and reliability — and not performing as expected [37]. Performance risk can be associated with both network outcomes (i.e. new product or service) or co-innovation platform performance [39]. The perceived social risk is defined as the potential loss of status in one's social group as a result of adopting a product or service [31], [35]. In collaborative networks, the actor's behavior or the outcomes of her behavior may result in possible disapproval by peers [40]. Perceived time risk refers to the time an actor may lose from learning how to participate or if the participation does not satisfy their expectations [37]. Perceived security or privacy risk is the expression of the actor's fear that the behavior could be harmful to privacy, such as potential loss of control over personal information [31], [34]. Lastly, perceived psychological risk refers to mental anxiety associated with a behavior [37].

As perceived risk is context-based, the specific dimensions utilized in the measurement model depend on the use context [31]. Therefore, for this study, we conducted a case study to select and adjust the dimensions based on the context of co-innovation before generating the measurement items.

\section{Case study}

Since the concept of co-innovation risks at the individual level has not been yet operationalized to our knowledge, a case study was used to support the construct development and generate an initial set of items. The case study helped us characterize risk as a set of vulnerabilities that negatively affect the actor's ability to achieve co-innovation goals [21], [22]. The case data were collected from a particular coinnovation network, Quirky. Quirky is a co-innovation network enabling its individual members to initiate and fully participate in new product development. As part of the Quirky ideation process, prospective inventors can submit their ideas for community evaluation. The submitted ideas, if selected, are collaboratively developed, and commercialized by network members. The developed product ideas are then put into production and then sold by the company.

Complementary data was collected from Quirky because its business model is more comprehensive than other networks due to the higher levels of actor involvement and the variety of co-innovation processes and social engagements. Therefore, the numerous co-innovation opportunities in this network along with the publicly available data provided a rich phenomenon to study. This case demonstrated a prototypical and, at the same time, a comprehensive model of co-innovation. Different data sources including observation and interview were used in this case study.

The first type of risk highlighted in the forum discussions and interview was IP risk in terms of potential loss due to use, abuse, or misuse of the actor's contribution by the company or other external actors without informing, getting permission, and providing fair compensation. This risk covered a diverse range of legally protected rights such as patents, copyrights, and designs, as well as other forms of intangibles such as human capital, and contract rights. Many actors believed that they are vulnerable to lose their right while participating in co-innovation.

The second most cited risk was financial risk (the potential for direct and indirect monetary loss) due to investment in the co-innovation activities. There is a risk that costs becoming bigger than the expected benefits of co-innovation. Quirky's members do not receive any monetary compensation if their ideas cannot make through the development process or the network structure limits some forms of financial compensations due to the internal rule or policies. Direct financial risk refers, for example, to losing submission fee due to unsuccessful new product idea. Indirect financial risks are associated with the financial investment in preparing a new idea, for example, preparing a product idea rendering.

Quirky's members were also concerned about losing time and inconvenience incurred due to failing to submit a winning idea or wasting time during collaboration due to incompetent collaborators or the processes complexity, for example. Co-innovation process is a time sensitive process due to the market competition and IP right recordation. Therefore, Quirky's members believe that the opportunity cost of time is high if the co-innovation project fails after long waiting time.

Lastly, some actors were concerned about losing their reputation in the Quirky socio-professional environment due to failures in co-innovation. The new category of perceived social or reputation risk involves the likelihood that co-innovation affects the way others think of the co-innovator since the Quirky publicly announces the actors' success and failure. We thus conceptualize reputation risk as the potential loss of status in one's social or professional group, as a result of contribution seems against the norm or the 
group standard. It is supported by the personal value theory claim about the risk perception within a social community [21]. This fact increases the perception of risk associated with reputation or social presence.

The case study revealed that the actors' intention to co-innovation depends on how they feel about the risks associated with all aspects of co-innovation behavior. We observed the importance of four out of six categories of risk namely financial, security (as intellectual property), time and social (as reputation) risks. The prior studies on perceived risk support the importance of all four dimensions [35] [41] [42].

Financial risk is the probability that actors will lose money as a result of co-innovation. Intellectual property (IP) right risk is the potential loss of control over IP without fair compensation, such as royalties, or use of the creative idea without actor's permission. Time risk refers to the time actors may lose by participating in co-innovation due to unsuccessful contribution or unproductive co-innovation process. The case result did not support the inclusion of performance and psychological risks. It might be because these dimensions are mainly related to the coinnovation process, not outcomes. It is reasonable as we conceptualized perceived risk as the expectation of losses in relationship to the actors' goals and not coinnovation process [35].

After conceptualizing the co-innovation risk as a multidimensional construct, the next step was the generation of items for sub-scales. Table 1 provides examples of items emerged from the case study. The questionnaire was developed based on the existing instrumented [31], [34], [35], [37] and then adjusted based on the insight from the case study.

Table 1. Examples of co-innovation risks

- Losing intellectual property rights

- Exploitation of product idea in another project

- Used product idea by other members

- Used product idea by company without ideator's knowledge, recognition, or compensation

- Losing invention opportunities

- Losing money by paying submission fee

- Losing money by collaborating for free (no reward)

- Losing money spent on idea preparation

- Losing time by working on new product idea

- Losing time by spending time on collaboration

- Losing time from having to learn how to collaborate

- Losing professional reputation due to failure in ideation

- Losing professional reputation due to unsuccessful collaboration

- Losing professional reputation due the final product failure in market

\section{Pre-test of scale items}

The items generated through the case study were refined into the measurement instrument through two processes: the pretest of the measurement items and the pretest of the questionnaire. These tests were conducted to identify problems in item selection and comprehension, so as to improve the content and face validity of the instrument.

First, measurement items and their categorization were examined through two rounds of card-sorting, which helped establish the face validity and confirmed the grouping and labeling within the context. Cardsorting was conducted in accordance with established guidelines [43]. This technique helped test the initial conceptualization and the classification of the proposed items. In both card-sorting exercises, the randomly listed items along with the names and definition of the constructs were distributed to 32 judges from our research community. The judges separately sorted each item to a most proper construct, marked it as 'Does not fit any category', or marked it as 'Does not make sense or is confusing.'

After the first card sorting, inter-rater reliabilities (Cohen's Kappa) were calculated to identify the problematic items. The Kappa scores met the acceptable level of 0.65 . In the first round, the judges sorted 24 items with the flexibility of adding new groups to the initial four groups. Five items were reworded based on the judges' feedback. After the refinement, the same procedure was followed for the second card-sorting but with judges from the target population. Thirty members of Quirky were invited to sort 19 items to four categories. This second phase of card-sorting indicated three redundant items, which were removed before the questionnaire pre-test.

\section{Pre-test of questionnaire}

The newly developed items were included in a questionnaire that examined co-innovation risk and co-innovation intention. All items were constructed as 7-point Likert-type scaled questions [44] to avoid collapsed variance and maintain the consistency of responses. The questions in each group were ordered randomly. We pretested the questionnaire using 'expert panel technique' recommended by Creswell [45]. This method helped identify the possible weaknesses in the construction of the questions such as possible sources of bias or order effects. First, ten senior researchers were invited to evaluate the questionnaire for respondent issues (e.g. comprehension, burden), as well as format issues (e.g. flow, typographical errors, and order effects). Experts reviewed the questionnaire and shared their opinion with the researcher directly.

The follow-up probes technique was employed next to identify difficulties in the questionnaire completion after revising the first draft based on expert feedback. In this stage, 20 graduate students familiar 
with co-innovation networks were invited to complete the questionnaire and comment on potential problems or improvement. Written and oral comments on the questionnaire were aggregately considered to improve the questionnaire. Finally, five reviewers were selected from the Quirky community for the third follow-up probes. Quirky members provided insights on the entire co-innovation process as well as the terminology used in the co-innovation community, facilitating further refinement and improvement.

\section{Measurement model specification}

We modeled co-innovation risk as a second-order formative construct [46] comprising of four first-order reflective constructs, namely Financial Risk, IP Right Risk, Socail Risk, and Time Risk (Figure 1). We used four criteria to determine the existence of a formative construct [46]-[49]: 1) the predictability of the risk construct by the proposed second order measures; 2) the sensitiveness of construct to the exclusion of any second-order measures; 3 ) the possibility of changing one measure without requiring a change in all other second-order measures of the construct; and 4) the existence of different antecedents and consequences for the second-order measures.

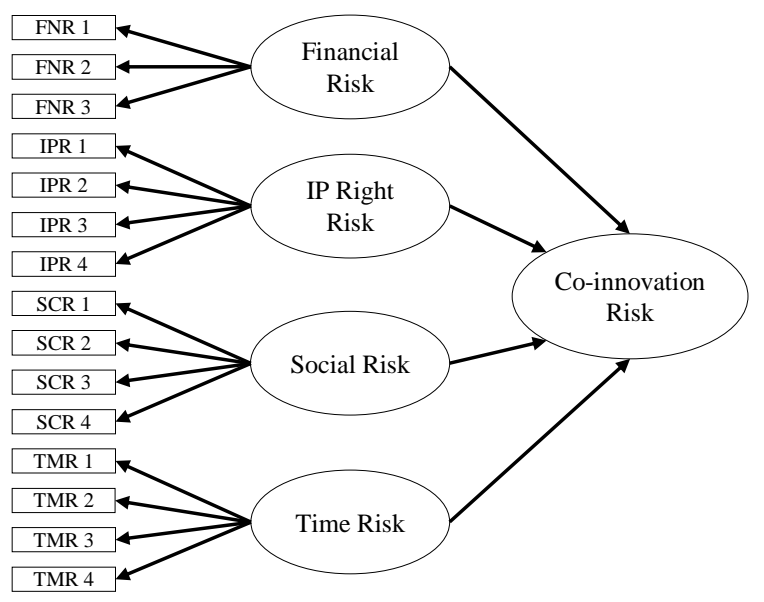

Figure 1: Reflective first-order, formative secondorder co-innovation risk construct

Regarding the predictability of the risk construct, our case study suggested that the four first-order constructs could exist independently of one another as each dimension of risk each can partially predict the level of co-innovation risk. Thus, measurements of financial risk, IP right risk, social risk, and time risk cannot substitute for each other in the measurement of the co-innovation risk. Omitting any one would alter the definition and comprehensiveness of the higherorder construct. There is also no empirical evidence or theoretical reason to expect the four second-order measures to be highly correlated and thus interchangeable. Lastly, four second-order measures can have different antecedents, and outcomes in terms of actor' behavior. For example, an actor may limit her ideation due to the risk of losing IP right but keep collaborating with other actors.

\section{Pilot studies}

We conducted a pilot study to make an initial reliability assessment of the sub-scales and improve the instrument to achieve the desired reliability levels. The pilot study was a full-scale pilot test of the questionnaire using respondents from the target population. The sample for the pilot study was drawn from the Quirky community and data were collected online. About 650 Quirky users were randomly selected and invited to participate in the pilot study. The respondents were also asked to provide feedback on the items, format, and scaling. The respondents were all active members with at least one-month experience in co-innovation. A total of 72 usable questionnaires were returned. Since data were normally distributed, this sample size was a reasonable size for multivariate analysis with SEM-PLS [50] using SmartPLS [51]. The measurement model was tested in two steps using the techniques recommended by Hair and colleagues [44], [45]. The first step was for first-order reflective construct examination and the latent variables estimation, and Step 2 was for formative second-order constructs.

First-order. Table 2 presents the overall quality of reflective measures. Cronbach's alpha and composite reliability were calculated to test the reliability of data. In this stage, FNR4 (e.g. losing money by joining the network) was the only indicator removed from the initial model with a factor loading less than 0.5. Before this item elimination, we checked the content validity to ensure that the domain coverage of the construct would not suffer. After removing FNR4, the Financial Risk composite reliability was improved to 0.916 and its Cronbach's alpha improved to 0.88 . The rest of reflective constructs met the reliability criteria.

Table 2. Reflective measures reliability

\begin{tabular}{lccc}
\hline & AVE & $\begin{array}{c}\text { Composite } \\
\text { Reliability }\end{array}$ & $\begin{array}{c}\text { Cronbach's } \\
\text { Alpha }\end{array}$ \\
\hline Financial Risk & 0.731 & 0.916 & 0.877 \\
IP Right Risk & 0.711 & 0.881 & 0.797 \\
Social Risk & 0.829 & 0.951 & 0.927 \\
Time Risk & 0.728 & 0.935 & 0.907 \\
\hline
\end{tabular}

Convergent validity of reflective constructs was tested by examining Average variance extracted (AVE). All constructs met the threshold of 0.5 . Discriminant 
validity was tested by Fornell-Larcker criterion and the examination of cross-loadings. Comparing the loadings indicated if an item's loadings on its own construct are in all cases higher than all of its cross loadings with other constructs. Moreover, the AVE of each reflective construct, was higher than the construct's highest squared correlation with any other construct. These tests supported the discriminant validity between all the dimensions of co-innovation risk. In addition, the evaluation of factor loading identified no cross-loading issues.

Second-order. The evaluation of the second-order construct as a formative construct included assessment of the formative indicators' validity, multicollinearity, convergent validity (redundancy). The estimation of indicator validity was performed using the PLS algorithm method with a bootstrapping of samples to calculate item weights and loading of each formative indicator. The t-values for each item's weight (relative importance) and loading (absolute importance) were significance. Multicollinearity tests showed that each indicator's variance inflation factor (VIF) value was less than the cut-off value of 5. Redundancy analysis was then conducted to establish the convergent validity by correlating each formative construct with a global measure for that construct. Path coefficients were above the threshold of 0.80 , providing support for the convergent validity of the formative constructs. For the sake of brevity, the detailed results of secondorder construct evaluation are not presented here as we repeated the same process for the field study.

Table 3. Final measurement items

\begin{tabular}{|c|c|}
\hline $\begin{array}{l}\text { Financial } \\
\text { Risk }\end{array}$ & $\begin{array}{l}\text { FNR1: losing money by ideation } \\
\text { FNR2: losing money by collaboration } \\
\text { FNR3: potential financial fraud }\end{array}$ \\
\hline $\begin{array}{l}\text { IP Right } \\
\text { Risk }\end{array}$ & $\begin{array}{l}\text { IPR1: losing IP rights } \\
\text { IPR2: idea exploitation by community } \\
\text { IPR3: use idea without acknowledgment } \\
\text { IPR4: idea exploitation by the company }\end{array}$ \\
\hline $\begin{array}{l}\text { Social } \\
\text { Risk }\end{array}$ & $\begin{array}{l}\text { SCR1: lowering esteem among friends by failure } \\
\text { SCR2: losing reputation because of wasting time } \\
\text { SCR3: losing reputation by showing off } \\
\text { SCR4: losing reputation by failure }\end{array}$ \\
\hline $\begin{array}{l}\text { Time } \\
\text { Risk }\end{array}$ & $\begin{array}{l}\text { TMR1: losing time by submitting a new product idea } \\
\text { TMR2: losing time by collaborating } \\
\text { TMR3: losing time by learning how to collaborate } \\
\text { TMR4: losing time by participating in discussions }\end{array}$ \\
\hline
\end{tabular}

\section{Field Study}

The final measurement items that were used in the field test are listed in Table 3. The data for the field survey were collected from a random sample of Quirky members. From 60,000 potential respondents, 1,000 Quirky members were randomly invited to participate in an online survey. Of the 320 Quirky's members who responded fifty-nine responses were removed due to the respondents' lack of co-innovation experience or incomplete data, leaving a final sample of 261 usable responses for analysis. Demographic data analysis shows that all relevant types of the respondent in terms of gender, age, education, and employment were included in the sample; therefore, the study obtained a productive and balanced sample. The vast majority of respondents had recent experience with ideation (82\%), collaboration (100\%), and/or communication (85\%) on Quirky.

Similar to the pilot test, the measurement models of co-innovation risk sub-scale were tested as four different first-order reflective constructs. Then, the second-order construct of co-innovation risk was examined as a four-dimensional formative construct.

First-order. The evaluation of the reflective measurement model included the test of indicator reliability, internal consistency, convergent validity, and discrimination validity. The loadings of the reflective indicators were examined in order to assess the indicator reliability. As presented in Table 4, all constructs were found to have "good" to "very good" factor loading. Internal consistency reliability (construct reliability) was assessed by examining the Composite Reliability and Cronbach's alpha of the constructs. Table 5 shows acceptable composite reliability values and Cronbach's alpha values for all the constructs, thus demonstrating acceptable internal consistency reliability for the first-order constructs.

Table 4. Co-innovation risk factor loadings

\begin{tabular}{ccccc}
\hline & $\begin{array}{c}\text { Financial } \\
\text { Risk }\end{array}$ & $\begin{array}{c}\text { IP Right } \\
\text { Risk }\end{array}$ & $\begin{array}{c}\text { Social } \\
\text { Risk }\end{array}$ & $\begin{array}{c}\text { Time } \\
\text { Risk }\end{array}$ \\
\hline FNR1 & 0.890 & & & \\
\hline FNR2 & 0.897 & & & \\
\hline FNR3 & 0.870 & & & \\
\hline IPR1 & 0.781 & & \\
\hline IPR2 & 0.904 & & \\
\hline IPR3 & 0.866 & & \\
\hline IPR4 & 0.891 & 0.918 & \\
\hline SCR1 & & 0.962 & \\
\hline SCR2 & & 0.949 & \\
\hline SCR3 & & 0.958 & \\
\hline SCR4 & & & 0.928 \\
\hline TMR1 & & & 0.891 \\
\hline TMR2 & & & \\
\hline TMR3 & & & \\
\hline TMR4 & & & \\
\hline
\end{tabular}

Convergent validity was again assessed using AVE. The acceptable standard is that the AVE of the constructs should exceed 0.5 , which means the items share at least half of their variance with the construct. Table 5 shows that the AVE values of the reflective measurement model of the research are greater than 0.5 with values ranging from 0.683 to 0.784 . These values provided evidence that the convergent validity was achieved and indicates that the measures used 
were robust. The discriminant validity of the model was evaluated by examining the cross loading for each indicator. It was found that the loading of each indicator with its own construct was higher than its loading for other constructs. Discriminant validity was also examined using the Fornell-Larcker criterion. The second evidence of discriminant validity, the AVE of each reflective construct, was higher than the construct's highest squared correlation with any other construct. Therefore, analysis of cross-loadings and Fornell-Larcker criterion showed that discriminant validity was perfectly established.

Table 5. Internal consistency reliability

\begin{tabular}{rccc}
\hline & AVE & $\begin{array}{c}\text { Composite } \\
\text { Reliability }\end{array}$ & $\begin{array}{c}\text { Cronbach's } \\
\text { Alpha }\end{array}$ \\
\hline Financial Risk & 0.784 & 0.916 & 0.864 \\
\hline IP Right Risk & 0.743 & 0.920 & 0.885 \\
\hline Social risk & 0.897 & 0.972 & 0.962 \\
\hline Time Risk & 0.811 & 0.945 & 0.922 \\
\hline
\end{tabular}

Second-order. The second-order formative construct was assessed following a guide recommended by Hair and his colleagues [52], [53]. Indicator validity was of interest for the test of the second-order construct of co-innovation risk. The estimation of this validity was performed using the PLS algorithm method with a bootstrapping of samples to calculate item weights and loading of each formative indicator. The number of bootstrap samples was 5,000, and the number of cases was equal to the number of observations in the original sample. Each item's weight, loading, and associated t-value using bootstrapping were used to assess items' significance. The weights and loadings of the formative indicators of the measurement model are given in Table 6. The second-order formative weights were only significant for FNR and TMR. Since both IPR and SCR sub-scale had significant loading value (respectively 0.53 and $0.72, p<0.00)$, there is empirical support to retain these items [49], [50]. Since the loadings were significant, keeping the all the items preserved the content validity of subscales [54].

Table 6. Weights and loadings

\begin{tabular}{|c|c|c|c|c|}
\hline & Loading & t-value & Weight & t-value \\
\hline Financial Risk & 0.837 & 8.072 & 0.442 & 0.037 \\
\hline IP Right Risk & 0.529 & 3.504 & -0.249 & 0.155 \\
\hline Social Risk & 0.727 & 4.553 & 0.231 & 0.267 \\
\hline Time Risk & 0.932 & 9.957 & 0.638 & 0.016 \\
\hline
\end{tabular}

Formative constructs were also evaluated for multicollinearity. Multicollinearity tests showed that each indicator's VIF value was less than the cut-off value of 5 (see, Table 7). Following the general guidelines of Hair et al., all formative indicators in this measurement model should be retained, as they were not highly correlated in the model [50].

Table 7. Formative indicator multicollinearity

\begin{tabular}{rcc}
\hline & Tolerance & VIF \\
\hline Financial Risk & 0.609 & 1.642 \\
\hline IP Right Risk & 0.449 & 2.229 \\
\hline Social risk & 0.669 & 1.495 \\
\hline Time Risk & 0.326 & 3.064 \\
\hline
\end{tabular}

Redundancy analysis was conducted to establish the convergent validity by correlating each formative construct with a single-item global measure for that construct. The path coefficients were above the threshold of $0.80(\mathrm{p}<0.01)$ supporting the convergent validity (i.e. not redundant variable).

The off-diagonal values in Table 8 are the square of correlations between the latent constructs. As the evidence of independency, the AVE of each reflective construct was higher than the construct's highest squared correlation with any other construct.

Table 8: Latent variable squared correlation

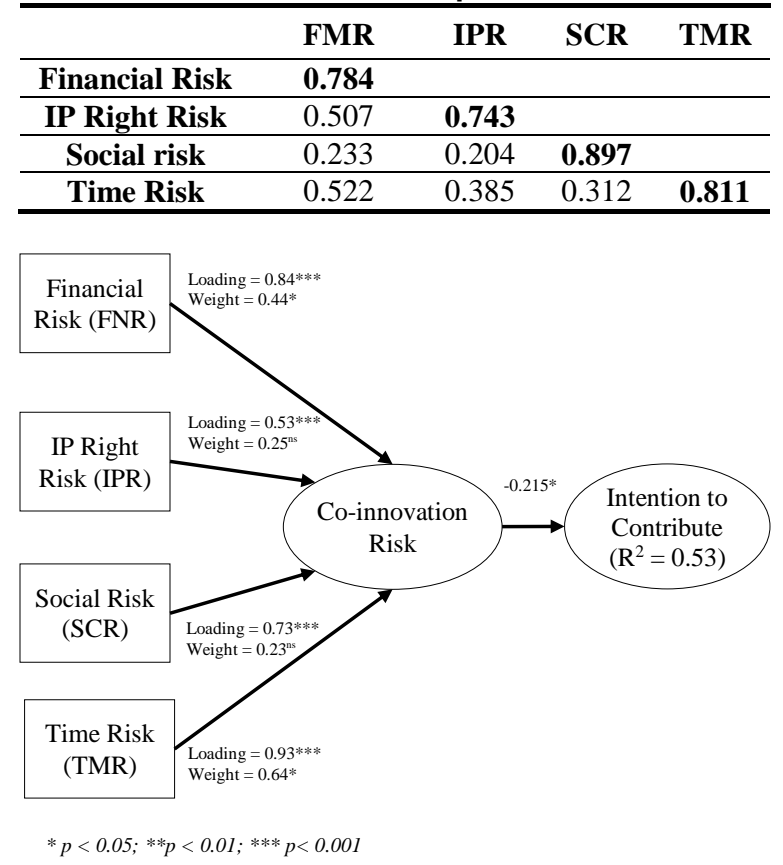

Figure 2. Test of predictive validity

Lastly, we examined the nomological or predictive validity by testing the relationship between the coinnovation risk construct and its consequence: actor intention to co-innovation (Figure 2). We assumed that perceived co-innovation risk has a direct relationship with an actor's goal-directed behavior. To support this claim we used the theory of goal-directed behavior, which explains that goal intention (or decision to perform a behavior) at cognitive stage involves a consideration of the risk and benefits of pursuing given goals [55]. IS literature shows that some 
cognitive factors such as a negative experience and risk can play a role in demotivation. Therefore, perceived individual risk can negatively affect the coinnovation behavior.

To test the predictive validity, we tested the significance of the direct effect between the coinnovation risk construct and intention to contribute using bootstrapping procedures. The results showed that co-innovation risk was negatively associated with intention to contribution $(b=-0.22, p<0.05)$.

Moreover, further analysis showed that coinnovation risk was also negatively associated with three dimensions of intention to contribute, namely intention to ideate $(b=-0.42, p<0.00)$, intention to collaborate $(b=-0.38, p<0.00$, and intention to communicate $(b=-0.22, p<0.05)$ (see, Table 9). As a result, we concluded that an actor's perception of coinnovation risk leads unfavorable or favorable perceptions of co-innovation that in turn affect their level and the intensity of participation in terms of ideation, collaboration, and communication.

Table 9: The relationships between risk and coinnovation behavior dimension

\begin{tabular}{lccc}
\hline & b & t & p \\
\hline $\begin{array}{l}\text { Co-innovation Risk } \rightarrow \\
\text { Intention to Ideate }\end{array}$ & -0.424 & 7.287 & 0.000 \\
\hline $\begin{array}{l}\text { Co-innovation Risk } \rightarrow \\
\text { Intention to Collaborate }\end{array}$ & -0.377 & 5.820 & 0.000 \\
\hline $\begin{array}{l}\text { Co-innovation Risk } \rightarrow \\
\text { Intention to Communicate }\end{array}$ & -0.215 & 2.115 & 0.035 \\
\hline
\end{tabular}

\section{Implications for theory $\&$ practice}

Risk perceived by actors is one of the key concerns in co-innovation business model implementations [56]. Westergren and Holmström note that managing risks in a co-innovation network is a key task for network coordinators [57]. By understanding different individual risk factors, network coordinators can minimize the risk of participation by adjusting relevant co-innovation processes, rules, and policies [58], and as a result, enhance actors' intentions to participate and contribute [59].

This study offers several contributions to coinnovation research, most notably, a valid and comprehensive instrument to measure co-innovation risk. In this study, co-innovation risk is operationalized by comprising four risk categories: financial risk, IP right risk, time risk and social risk. Our field test confirmed that the four co-innovation risk dimensions can be viewed as components of a second-order formative construct. The final result is a reliable measurement instrument with 15 items in four sub-scales.
This instrument can be used to investigate how the perception of co-innovation risk affects actor intention to contribute to co-innovation. In addition to the solid results for construct validity, the predictive validity of the construct is promising. We believe that the final instrument can contribute to research aimed at predicting co-innovation behavior in terms of general intention to co-innovate, or more specifically, intention for ideation, collaboration, and communication.

Understanding co-innovation risks at the actor level can also help organizations acquire, encourage, and retain external actors more efficiently, which is ultimately followed by better business outcomes. Once risks are assessed, measured and monitored, coinnovation networks can control, mitigate and eliminate its effects on the network productivity, stability, and sustainability. This study also highlighted the importance of managing perceived risk) by showing their negative impact on ideation, collaboration, and communication.

The findings also have prescriptive value in the coinnovation network governance. Co-innovation networks can consider the factors identified in this study in policy making, regulation development, and risk communication. The first step of risk management can consist of using the proposed measurement model in identifying risks and their effects on actors' participation and contribution. The second phase can be risk mitigation that consists of prioritizing, implementing, and maintaining the appropriate riskreducing measures recommended by the first phase, the risk assessment process. Following this phase, the instrument can be used in the continual evaluation of the mitigation strategies implemented to improve the co-innovation outcomes.

\section{Limitations and future studies}

In recommending this instrument, we should also note its limitations. While the instrument was developed to be as general as possible, it was tested with members of a particular type of co-innovation network. Although this instrument could be easily adapted for different co-innovation business models, additional checks for validity and reliability would be prudent. The study calls for more scholarly attention to the role perceived risk plays in influencing coinnovation behavior. We suggest that researchers employ the proposed instrument to develop new, more rigorous studies to further clarify the role of coinnovation risk. For example, further investigation is needed with other open innovation models to investigate the generalizability of the model as well as its impacts on co-innovation behavior including contribution rate and quality. 


\section{References}

[1] P. A. Gloor, Swarm creativity: competitive advantage through collaborative innovation networks. New York: Oxford University Press, 2006.

[2] B. Leavy, "Collaborative innovation as the new imperative - design thinking, value co-creation and the power of 'pull,"' Strateg. Leadersh., vol. 40, no. 2, pp. 2534, 2012.

[3] S. M. Lee, D. L. Olson, and S. Trimi, "Co-innovation: convergenomics, collaboration, and co-creation for organizational values," Manag. Decis., vol. 50, no. 5, pp. 817-831, 2012.

[4] J. Rosas, P. Macedo, A. Tenera, A. Abreu, and P. Urze, "Risk Assessment in Open Innovation Networks," in Risks and Resilience of Collaborative Networks, Springer, 2015, pp. 27-38.

[5] K. Abhari, E. Davidson, and B. Xiao, "Taking Open Innovation to the Next Level: A Conceptual Model of Social Product Development (SPD)," AMCIS 2016 Proc., 2016.

[6] M. Paulini, P. Murty, and M. L. M. Maher, "Design processes in collective innovation communities," CoDesign, vol. 9, no. 2, pp. 90-112, Jun. 2013.

[7] A. Von Raesfeld, P. Geurts, and M. Jansen, "When is a network a nexus for innovation? A study of public nanotechnology R\&D projects in the Netherlands," Ind. Mark. Manag., vol. 41, no. 5, pp. 752-758, Jul. 2012.

[8] W. Song, X. Ming, and P. Wang, "Collaborative product innovation network: Status review, framework, and technology solutions," Concurr. Eng., vol. 21, no. 1, pp. 5564, Dec. 2013.

[9] D. Kahnert, R. Menez, and B. Blättel-Mink, "Coordination and Motivation of Customer Contribution as Social Innovation: The Case of Crytek," in Challenge Social Innovation: Potentials for Business, Social Entrepreneurship, Welfare and Civil Society, H. W. Franz, J. Hochgerner, and J. Howaldt, Eds. Springer, 2012, pp. 293-306.

[10] B. T. Brown and J. Wyatt, "Design Thinking for Social Innovation," Stanford Soc. Innov. Rev., vol. Winter, pp. 30$35,2010$.

[11] D. Harrisson, J.-L. Klein, and P. L. Browne, "Social innovation, social enterprise and services," in The handbook of innovation and services: A multi-disciplinary perspective, F. Gallouj and F. Djellal, Eds. Edward Elgar Publishing, 2011, pp. 197-218.

[12] A. Martini, S. Massa, and S. Testa, "The Role of Social Software for Customer Co-Creation: Does It Change the Practice for Innovation? Regular Paper," Int. J. Eng. Bus. Manag., vol. 4, no. 1, pp. 1-10, 2012.

[13] F. Piller, A. Vossen, and C. Ihl, "From Social Media to Social Product Development: The Impact of Social Media on Co-Creation of Innovation," Die Unternehmung, vol. 65, no. 1, pp. 7-27, 2012.
[14] M. Bertoni, A. Larsson, A. Ericson, K. Chirumalla, T. Larsson, O. Isaksson, and D. Randall, "The Rise of Social Product Development," Int. J. Netw. Virtual Organ., vol. 11, no. 2, pp. 188-207, 2012.

[15] P. Murty, M. Paulini, and M. Maher, "Collective Intelligence and Design Thinking," in In DTRS'10: Design Thinking Research Symposium, 2010, pp. 309-315.

[16] J. Byrd and P. L. Brown, The innovation equation: Building creativity and risk taking in your organization. Jossey-Bass/Pfeiffer, 2003.

[17] E. L. Coras and A. D. Tantau, "Open Innovation - the Good, the Bad, the Uncertainties," USV Ann. Econ. Public Adm., vol. 14, no. 19, pp. 38-47, 2014.

[18] E. L. Coras and A. D. Tantau, "A Risk Mitigation Model in SME'S Open Innovation Projects.," Manag. Mark., vol. 8, no. 6, pp. 303-328, 2013.

[19] D. Romero and A. Molina, "Collaborative networked organisations and customer communities: value co-creation and co-innovation in the networking era," Prod. Plan. Control, vol. 22, no. 5-6, pp. 447-472, Jul. 2011.

[20] E. Enkel, O. Gassmann, and H. Chesbrough, "Open R\&D and open innovation: exploring the phenomenon," R\&D Manag., vol. 39, no. 4, pp. 311-316, 2009.

[21] L. Souza, I. Ramos, and J. Esteves, "Crowdsourcing Innovation: A Risk Management Approach," in MCIS 2009 Proceedings, 2009, pp. 763-774.

[22] O. Renn, "The role of risk perception for risk management," Reliab. Eng. Syst. Saf., vol. 59, no. 1, pp. 4962,1998

[23] D. Romero, A. Molina, and L. M. Camarinha-Matos, "Co-innovation and collaborative networks," Prod. Plan. Control, vol. 22, no. 5-6, pp. 445-446, Jul. 2011.

[24] V. Grover and R. Kohli, "Cocreating IT Value: New Capabilities and Metrics for Multifirm Environments," MIS $Q$, vol. 36, no. 1, pp. 225-232, 2012.

[25] P. Shamdasani, A. Mukherjee, and N. Malhotra, "Antecedents and consequences of service quality in consumer evaluation of self-service internet technologies," Serv. Ind. J., vol. 28, no. 1, pp. 117-138, 2008.

[26] S. S. Mishra and K. B. Saji, "The impact of institutional variables in new high-tech product development processes: The moderating roles of perceived risk and project duration," Mark. Intell. Plan., vol. 31, no. 4, pp. 160-178, 2013.

[27] A. Martini, S. Massa, and S. Testa, "The firm, the platform and the customer: A 'double mangle' interpretation of social media for innovation," Inf. Organ., vol. 23, no. 3, pp. 198-213, 2013.

[28] S. B. MacKenzie, P. M. Podsakoff, and N. P. Podsakoff, "Construct measurement and validation procedures in MIS and behavioral research: integrating new and existing techniques," MIS Q., vol. 35, no. 2, pp. 293-334, 2011. 
[29] G. R. Dowling, "Perceived risk: The concept and its measurement," Psychol. Mark., vol. 3, no. 3, pp. 193-210, 1986.

[30] R. A. Bauer, "Consumer Behaviour as Risk Taking," in Risk Taking and Information Handling in Consumer Behavior, D. F. Cox, Ed. Boston, MA: Harvard University Press, 1967, pp. 23-33.

[31] M. Cocosila, N. Archer, and Y. Yuan, "Early investigation of new information technology acceptance: A perceived risk-motivation model," Commun. Assoc. Inf. Syst., vol. 25, no. 1, p. 30, 2009.

[32] J. P. Peter and M. J. Ryan, "An investigation of perceived risk at the brand level," J. Mark. Res., vol. 13, no. 2, pp. 184-188, 1976.

[33] S. Alter and S. A. Sherer, "A general, but readily adaptable model of information system risk," Commun. Assoc. Inf. Syst., vol. 14, no. 1, pp. 1-28, 2004.

[34] E. U. Weber, A.-R. Blais, and N. E. Betz, "A domainspecific risk-attitude scale: Measuring risk perceptions and risk behaviors," J. Behav. Decis. Mak., vol. 15, no. 4, pp. 263-290, 2002.

[35] M. S. Featherman and P. A. Pavlou, "Predicting eservices adoption: a perceived risk facets perspective," Int. J. Hum. Comput. Stud., vol. 59, no. 4, pp. 451-474, Oct. 2003.

[36] V. M. Cunningham, X. Corporate, M. Services, and X. L. Six, "Six Sigma and Business Marketing," Building, pp. 1-66, 2005.

[37] M. S. Featherman and N. Hajli, "Self-service technologies and e-services risks in social commerce era," $J$. Bus. Ethics, pp. 1-19, 2015.

[38] M. Featherman, R. T. Wright, J. B. Thatcher, J. C. Zimmer, and R. Pak, "The influence of interactivity on eservice offerings: An empirical examination of benefits and risks," AIS Trans. Human-Computer Interact., vol. 3, no. 1, pp. 1-25, 2011.

[39] U. Schultze, E. Prandelli, P. I. Salonen, and M. Van Alstyne, "Internet-enabled co-production: Partnering or competing with customers?," Commun. Assoc. Inf. Syst., vol. 19, no. 1, p. 15, 2007.

[40] R. Krishnan, M. D. Smith, and R. Telang, "The economics of peer-to-peer networks," J. Inf. Technol. Theory Appl., vol. 5, no. 3, pp. 31-44, 2003.

[41] A. M. Hassan, M. B. Kunz, A. W. Pearson, and F. A. Mohamed, "Conceptualization and measurement of perceived risk in online shopping," Mark. Manag. J., vol. 16, no. 1, pp. 138-147, 2006.

[42] C. Boshoff, C. Schlechter, S. Ward, C. Schlechter, and S. Ward, "Consumers perceived risks associated with purchasing on a branded web site: the mediating effect of brand knowledge," South Afric. J. Bus. Manag., vol. 42, no. 1, pp. 45-55, 2011.

[43] G. C. Moore and I. Benbasat, "Development of an Instrument to Measure the Perceptions of Adopting an Information Technology Innovation," Inf. Syst. Res., vol. 2, no. 3, pp. 192-222, Sep. 1991.

[44] S. Jamieson, "Likert scales: how to (ab) use them," Med. Educ., vol. 38, no. 12, pp. 1217-1218, 2004.

[45] J. W. Creswell, Research Design: Qualitative, Quantitative, and Mixed Methods Approaches. SAGE Publications, 2013.

[46] C. B. Jarvis, S. B. Mackenzie, and P. M. Podsakoff, "A Critical Review of Construct Indicators and Measurement Model Misspecification in Marketing and Consumer Research," J. Consum. Res., vol. 30, no. September 2003, 2004.

[47] R. T. Cenfetelli and G. Bassellier, "Interpretation of Formative Measurement in Information Systems Research," MIS Q., vol. 33, pp. 689-707, 2009.

[48] S. Petter, D. Straub, and A. Rai, "Specifying formative constructs in information systems research," MIS Q., vol. 31, pp. 623-656, 2007.

[49] A. Diamantopoulos and H. M. Winklhofer, "Index construction with formative indicators: An alternative to scale development," J. Mark. Res., vol. 38, no. 2, pp. 269277, 2001.

[50] J. F. Hair and R. E. Anderson, Multivariate data analysis. Prentice Hall Higher Education, 2010.

[51] C. Ringle, S. Wende, and J. Becker, "SmartPLS 3," Boenningstedt: SmartPLS GmbH. 2015.

[52] J. F. Hair, C. M. Ringle, and M. Sarstedt, "PLS-SEM: Indeed a Silver Bullet," J. Mark. Theory Pract., vol. 19, no. 2, pp. 139-152, Apr. 2011.

[53] J. F. Hair, G. T. M. Hult, C. Ringle, and M. Sarstedt, $A$ Primer on Partial Least Squares Structural Equation Modeling (PLS-SEM). SAGE Publications, 2013.

[54] K. Bollen and R. Lennox, "Conventional wisdom on measurement: A structural equation perspective.," Psychol. Bull., vol. 110, no. 2, pp. 305-314, 1991.

[55] M. Conner and C. J. Armitage, "Extending the Theory of Planned Behavior: A Review and Avenues for Further Research," J. Appl. Soc. Psychol., vol. 28, no. 15, pp. 14291464, Aug. 1998.

[56] H. Rahman and I. Ramos, "Open Innovation in SMEs : From Closed Boundaries to Networked Paradigm," Issues Informing Sci. Inf. Technol., vol. 7, no. 4, pp. 471-487, 2010.

[57] U. H. Westergren and J. Holmström, "Exploring preconditions for open innovation: Value networks in industrial firms," Inf. Organ., vol. 22, no. 4, pp. 209-226, Oct. 2012.

[58] A. H. Van de Ven, "Running in packs to develop knowledge-intensive technologies," MIS Q., pp. 365-377, 2005.

[59] O. M. Confusion, C. C. Co-design, O. Communities, C. Communication, F. Piller, P. Schubert, M. Koch, and K. Möslein, "Overcoming Mass Confusion: Collaborative Customer Co-Design in Online Communities," J. Comput. Commun., vol. 10, no. 4, pp. 00-00, Jun. 2006. 